\title{
Precaution or Integrated Responsibility Approach to Nanovaccines in Fish Farming? A Critical Appraisal of the UNESCO Precautionary Principle
}

\author{
Anne Ingeborg Myhr • Bjørn K. Myskja
}

Received: 14 December 2010 / Accepted: 6 March 2011 /Published online: 5 April 2011

(C) The Author(s) 2011. This article is published with open access at Springerlink.com

\begin{abstract}
Nanoparticles have multifaceted advantages in drug administration as vaccine delivery and hence hold promises for improving protection of farmed fish against diseases caused by pathogens. However, there are concerns that the benefits associated with distribution of nanoparticles may also be accompanied with risks to the environment and health. The complexity of the natural and social systems involved implies that the information acquired in quantified risk assessments may be inadequate for evidence-based decisions. One controversial strategy for dealing with this kind of uncertainty is the precautionary principle. A few years ago, an UNESCO expert group suggested a new approach for implementation of the principle. Here we compare the UNESCO principle with earlier versions and explore the advantages and disadvantages by employing the UNESCO version to the use of PLGA nanoparticles for delivery of vaccines in aquaculture. Finally, we discuss whether a combined scientific and
\end{abstract}

A. I. Myhr $(\bowtie)$

GenØk-Centre for Biosafety,

Forskningsparken, Breivika, NO 9294,

Tromsø, Norway

e-mail: anne.i.myhr@uit.no

B. K. Myskja

Department of Philosophy,

Norwegian University of Science and Technology,

NO 7491,

Trondheim, Norway

e-mail: bjorn.myskja@ntnu.no ethical analysis that involves the concept of responsibility will enable approaches that can provide a supplement to the precautionary principle as basis for decision-making in areas of scientific uncertainty, such as the application of nanoparticles in the vaccination of farmed fish.

Keywords The precautionary principle $\cdot$ Ethics . Scientific uncertainty $\cdot$ Nanoparticle $\cdot$ Aquaculture Responsibility

\section{Introduction}

Biocompatible and biodegradable polymer-based particles may be advantageous for drug delivery purposes and medicinal applications. Of these polymers, polylactides (PLA) and poly (-lactide-co-glycolide) (PLGA) have been the most extensively investigated for drug delivery [29]. Polymeric nanoparticles have several advantages in vaccine delivery; they can provide sustained delivery of vaccines, they can solubilize drugs for intravascular delivery, and they can improve solubility of vaccine antigens against enzymatic degradation. PLGA encapsulated DNA encoding antigens are protected against enzymatic digestion and can therefore be released over extended periods of time. Within aquaculture one of the most important constraints for further growth is the prevalence of diseases. This has caused intensive search for novel and improved vaccines. One new 
interesting possibility is the use of nanoparticles for delivery of vaccines, as for example PLGAs. Most projects involving the use of PLGAs is still under development, and has been most extensively studied for human and animal use where rodents is used as research animal, while only a few studies has been published where fish is the main target [37]. On the other hand, there is at present limited scientific understanding of the mechanisms underlying uptake and persistence of PLGA as nanoparticles after injection into an animal [29]. Main areas of uncertainty are with regard to the immunological and toxicological impact, biodistribution and degradability after injection and whether the polymeric nanoparticles can be distributed to the environment. The present lack of scientific understanding of the health and environmental effects of distribution of nanoparticles involves a challenge with regard to risk assessment and management.

PLGAs have at the macrolevel been used in medical applications and hence provide some understanding with regard to persistence, distribution and side-effects [1]. When we turn to the use of PLGA for delivery of vaccines at the nanolevel, new questions arise. For example whether the reduction of size involves new uncertainties, if the use on a new target animal, fish, may cause novel effects and if the particles can spread to surrounding environments with unforeseen consequences. All these questions are relevant with regard to identification of potential harmful consequences when PLGAs are used in vaccines. One controversial strategy for dealing with this kind of uncertainty in regulation is the precautionary principle, which will be the main topic of the subsequent discussion.

Given that we have different degrees of knowledge regarding assumptions of harmful consequences, it is reasonable that these possible harms should be dealt with according to different principles. In cases where we have sufficient experience to quantify the probabilities, risk assessments is the commonly accepted way to handle the problems. There are of course different degrees of subjectivity regarding the estimates as well as the value assessments involved, but these are usually handled by a scientifically based discourse. In cases of uncertainty one can argue for the use of different principles, including a more or less subjectively based version of risk assessment, given that the usual experiential basis for quantifying risk is deficient. An alternative is the conservative maximin or minimax principle, proposing that one should minimize maximum harm. In the international governance debate, however, the majority has supported different versions of the precautionary principle.

But it is not obvious that these methods for dealing with uncertainty are relevant for the issue we are facing, namely how to handle the possible risks in nanotechnology application such as the use of PLGA particles in fish vaccination. A case can be made that we are primarily in a situation of scientific ignorance regarding nanotechnology, and that we have no basis for making plausible hypotheses about causal relationships and mechanisms leading to harm. What we are left with may be mere unfounded speculations where one guess may be as good as the next, and given that technology applications will lead to harm, they may be of a radically different nature from the ones proposed at such early stages. If this is the case, precaution is not an alternative, as all versions of the principle demand some kind of plausible harm scenario as basis for instigating precautionary measures.

This line of argument has some merit in regard to nanotechnology in general. We are in a state of ignorance regarding both the benefits and harms that may result from this interdisciplinary research in a wide range of technology areas. This problem is not the same regarding particular technology applications, or at least, not all of them. The case we are discussing is one where we can draw up some plausible harm scenarios based on what we know about the particles in question from the use at the macrolevel, as well as knowledge within vaccinology and about farmed salmon and marine ecology. Although some harm scenarios are beyond precaution due to deficient knowledge, others clearly are not. We will assume that the epistemic conditions are on a scale from probable harm scenarios which should be subjected to risk assessment, via plausible harm scenarios calling for some kind of precautionary or related regulatory measures, to more or less speculative scenarios where potential harm is a matter of speculation, similar to the hyping of potential nanotechnology benefits. In this latter case, there is no scientific basis for regulatory measures. But there are a number of issues concerning the use of PLGA nanoparticles in fish vaccines that should be classified as a matter of scientific uncertainty, and in these cases there are grounds for suggesting some kind of regulation even in the absence of data enabling quantified risk assessments. 
The precautionary principle has been accepted by many national governments as a basis for policymaking, and it has become important both in international environmental law and international treaties $[5,10,11,38]$. Implementation of the precautionary principle entails three interrelated proposals: the first one concerns caution in the face of application of new technology, the other emphasizes the importance of conducting risk associated research, and the third entails that precautionary actions need to be taken. In this paper our focus is on the first proposal -the policy decision to trigger the precautionary principle. The implementation of the precautionary principle in political decisions is and has been a subject of heated scientific and public controversies $[17,34]$. So-called weak versions are criticized as being vacuous. The paradigmatic example is found in the declaration issued by the Rio Conference on Environment and Development:

'Where there are threats of serious or irreversible damage, lack of full scientific certainty shall not be used as a reason for postponing costeffective measures to prevent environmental degradation' [50]

The formulation 'lack of full scientific certainty' implies that some degree of scientific certainty is required. But when there is some certainty, it is usually possible to make fairly good risk assessments, and precaution becomes superfluous. The demand of cost-effectiveness is also held to undermine the reduced burden of proof required to instigate precautionary measures.

Strong versions are argued to be detrimental to scientific and economic development. These versions are held to place unreasonable regulatory burdens on new technology utilization, reducing returns from innovation, limit utilization of technology worldwide and providing disincentives for research. A typical example is the Wingspread version:

'When an activity raises threats of harm to human health or the environment, precautionary measures should be taken even if some causeand-effect relationships are not fully established scientifically. In this context, the proponent of an activity, rather than the public, should bear the burden of proof.' [41]
Adding to this criticism of the principle as being either too weak or too strong is the number of competing definitions of the precautionary principle, leading to further difficulties for implementation in legislation and employment in actual cases. In the following we intend to highlight some advantages and disadvantages with the UNESCO version compared to other versions of the precautionary principle, using PLGA particles for delivery of vaccines as a case study. We will argue that the UNESCO version of the precautionary principle evades some of the consequences that have been criticized in earlier versions. However, also the UNESCO version has problematic aspects that we will describe. Moreover, we discuss to what extent a combined scientific and ethical analysis that involves the concept of responsibility will improve the basis for decision-making under scientific uncertainty and thereby contribute to a socially robust development and application of nanoparticles for delivery of vaccines.

\section{The Precautionary Principle; The Adequacy of Weak and Strong Versions}

The precautionary principle is a normative principle for making practical decisions under conditions of scientific uncertainty. Gardiner [15] suggests that the following elements are essential to the principle:

- Threat of harm

- Uncertainty of impact or causality

- Precautionary response

As we can see this raises a host of questions, with regard to how to define harm, how to assess and systematize uncertainty and when and how to initiate a precautionary response. The actual content of the precautionary principle and the practical implications of its implementation in policy issues are controversial $[14,35,54]$. Several formulations of the principle, ranging from ecocentric to anthropocentric, and from risk-adverse to risk-taking positions, have been put forward.

Weak versions of the precautionary principle are often grounded in narrow utilitarian ethics, and applications involve risk/cost-benefit analyses. In this context, the principle may be used as an option to manage risks when they have been identified through risk analysis. For example, the Rio Declaration 
employs the weighing of costs and benefits, and similar wording has been reproduced in the preamble of the Convention on Biological Diversity and in article 3 of the Framework Convention on Climate Change. Strong versions are active in nature, shift the burden of proof to the proponents of the activity and oblige regulators to take action, for instance by implementation of risk management procedures [54].

Weak versions of the principle are criticized as vacuous, whereas strong versions are often considered too narrow, focusing on environmental risk without considering the costs of existing practices to the environment or taking into account relevant nonenvironmental concerns [15,25]. For instance, employment of a weak version of the precautionary principle to PLGA as carriers of vaccines in aquaculture would focus on the proposed benefits while the potential risks to health and the environment would be downplayed due to the present lack of scientific understanding. Weiss [52] demonstrates the motivation behind weak approaches when he states, 'desirable innovations can be blocked by an excess of precaution'. He proposes to prevent this excess by introducing 'a new principle of Innovation and Adaptive management, to the effect that precautionary action should not unreasonably interfere with an innovation that promises major benefits until the dangers and benefits of this innovation are well understood' [52]. Postponing intervention waiting for evidence of harm, as Weiss suggests, empties the precautionary principle of content. This demonstrates that a 'wait-and-see-strategy' is opposed to the precautionary principle, and must rather be regarded as an alternative strategy. Postponing intervention may in some circumstances be an option depending on the state of understanding and the possibility for reversibility of the hazards caused by the technology. The wait-and see-strategy as a way to undermine the rationale of precaution is a common criticism of weak versions. If the PLGA nanoparticles showed promising results in vaccination, the version would recommend use even if there were plausible grounds for suspecting environmental harm, as long as the basis for determining the level of harm was insufficient.

On the other hand, a strong precautionary assessment of polymeric nanoparticles applications for example based on the Wingspread statement, would tend to emphasize the risks of using them, neglecting detrimental effects of the existing vaccination practi- ces, as well as the potentially positive effect of more effective vaccines for food production and enhancement of animal welfare.

Although there is leveled reasonable critique against strong and weak versions, the complex challenges by scientific uncertainties must be dealt with in some way or another. First, because there is general agreement that we are politically and morally obliged to avoid foreseeable harm [20]. Second, because the present controversy on how to deal with unintended effects due to employment of new technology is an issue that we need to resolve on its own account [9]. Furthermore, full certainty about potential unintended health and environmental effects is unattainable prior to full-scale employment of the technology. The complexity of animal and environmental systems implies that the information achieved by doing laboratory research and in risk assessment is not adequate for evidence-based decisions. Thus, the reasons for introducing the precautionary principle, namely how to approach and acknowledge lack of scientific understanding in political decisions, is as relevant today as in the early Nineties.

\section{Implementation of the Precautionary Principle}

The implementation of the precautionary principle requires that there are indications of adverse impacts, and that risk-associated research is initiated. Hence, indications of adverse impacts must be documented in a scientifically acceptable way before a precautionary measure can be initiated. What is held to be acceptable evidence for action differs markedly in weak and strong versions of the precautionary principle. For example, Article 15(1) of the Cartagena Protocol on Biosafety states that;

'Risk assessments undertaken pursuant to this Protocol shall be carried out in a scientifically sound manner ... Such risk assessments shall be based, at a minimum, on information provided in accordance with Article 8 and other available scientific evidence in order to identify and evaluate the possible adverse effects of living modified organisms on the conservation and sustainable use of biological diversity, taking also into account risks to human health.' 
Usually what is regarded as scientific evidence is connected to quantifiability, and scientific soundness is likewise associated with quantified science. For instance, a typical example of a systematized quantified risk approach to genetically modified organisms is the principle of substantial equivalence [27]. As long as we are talking about risk, quantified evidence means measuring probability of an identified undesirable effect. By demanding scientific evidence before employing the precautionary principle, the Biosafety Protocol requires documentation indicating that the genetically modified organism in question causes harm to health or the environment.

The EC communication on the precautionary principle [10], on the other hand, focuses on the quality of the information. A focus on the quality of information relates to what type of scientific understanding is known and what there is a lack of information about-without requiring 'degrees' or 'levels' of proof, expressed as quantified probabilities. Hence, scientific uncertainty and indications of harm would be enough for acceptance of employment of the precautionary principle. The first approach corresponds to a weak version of the principle, whereas the second indicates a strong version. The weak version demands measurements, which presupposes that we possess the kind of knowledge that would make precaution superfluous. Accordingly, we would be better off with standard risk assessments. However, the strong version may open up for endless negotiations as to what is uncertain and unknown, as well as what should count as indications of the 'unknown'. In addition, the strong versions tend to overemphasize the potential adverse impact of the proposed action as compared to the situation this action seeks to amend or improve, resulting in a presumption for postponement of technology implementation based on an arguably one-sided risk focus.

Thus, a demand that there need to be available scientific information to determine whether precautionary steps should be taken, fails to evade the criticism of weak versions of the principle for being vacuous. On the other hand, the postponement of scientific assessments in the strong versions combined with the myopic focus on indications of environmental risk, may fail to balance the risks with benefits or, in other cases, risks of non-action.

\section{The UNESCO Version of the Precautionary Principle}

The recent UNESCO report on the precautionary principle [49] may indicate a promising middle ground between the present strong and weak versions. One reason is that it gives a thick description of the issues at stake, incorporating various ethical values concerning intra- and inter-generational equity, environmental responsibility, sustainable development and stakeholder participation. The UNESCO version replaces scientific probability with plausibility, and also emphasizes that uncertainty is the trigger for application of the precautionary principle. Furthermore, it defines the limits of the principle by stating that 'if a hypothesis posits radically new and unfamiliar mechanisms and processes, it is not plausible'; in which case the principle is not relevant. Moreover, the UNESCO principle involves evaluation of the consequences of both action and inaction in a participatory process. Accordingly some of the pitfalls of both weak and strong versions seem to be avoided:

'When human activities may lead to morally unacceptable harm that is scientifically plausible but uncertain, actions shall be taken to avoid or diminish that harm.

Morally unacceptable harm refers to harm to humans or the environment that is

- threatening to human life or health, or

- serious and effectively irreversible, or

- inequitable to present or future generations, or

- imposed without adequate consideration of the human rights of those affected.

The judgment of plausibility should be grounded in scientific analysis. Analysis should be ongoing so that chosen actions are subject to review.

Uncertainty may apply to, but need not be limited to, causality or the bounds of the possible harm.

Actions are interventions that are undertaken before harm occurs that seek to avoid or diminish the harm. Actions should be chosen that are proportional to the seriousness of the potential harm, with consideration of their positive and negative consequences, and with an assessment of the moral implications of both action and inaction. The choice of action should be the result of a participatory process.' 
Due to the level of detail, this version gives a more comprehensive account than the ones we have discussed above. It is specific concerning what kind of harm that is basis for precautionary action, thus evading the critique that the principle is either too vague or too demanding. Unlike weak versions, the UNESCO principle does not demand scientific certainty or evidence of benefits and harm prior to action. Unlike strong versions it does not focus only on the negative potential of the proposed activity, but requires an assessment of inaction as well as action. This version involves no shift of the burden of proof, as the Wingspread statement does, and is arguably less problematic concerning technology implementation.

Still, this version may face the charge of being unclear on key issues, at least if the precautionary principle is intended to be action guiding. This is clearly the case with the phrase "morally unacceptable harm' and its specifications 'threatening to life or health', 'serious and irreversible' and 'inequitable'. Some guidance is however given in the UNESCO report by its reference to participatory mechanisms and democratic pluralism and the insistence on the need for case-based reflective value judgments: 'A strength of the precautionary principle being a principle is its open-endedness and flexibility, which creates a possibility and an incentive for social learning.' (p.51). In the following we will further elaborate on these points, bearing in mind that the report proposes a procedure rather than a recipe for dealing with particular cases of scientific uncertainty regarding harm, using introduction of PLGA for delivery of vaccines in aquaculture as our case study.

\section{Threatening to Human Life or Health}

The purpose of vaccination is to protect fish against disease, with the intention to improve animal welfare and the economy of aquaculture. All fish in commercial aquaculture is meant for human consumption, hence this raises the issue of safety for consumption. To the best of knowledge of the authors no studies on the implications of eating PLGA mediated vaccinated fish exists. If, however, someone presented a scientifically plausible scenario of the PLGA nanoparticles not being fully degraded and having toxic effects, we have a situation similar to the scientific controversy surrounding the uncer- tainties of the effects on human and animal health by consumption of genetically modified foods. Although highly contested within science [13,51], there are reasonable scientific arguments for caution, for example based on documented unintended effects in different kinds of breeding and gene modification, combined with the fact that absence of proof of harm is not equal to proof of absence of harm. But this falls back on the question of how to decide that an indication of harm is to be considered scientifically plausible. Only the scientific community can decide that, and as stated in the UNESCO version 'The judgment of plausibility should be grounded in scientific analysis'. However, as illustrated above there are significant disagreements between scientists on matters such as these, depending on their training and work context [28]. What is plausible for one scientist is highly unlikely for another, depending on their perspective. One could counter this by saying that a situation with scientific disagreement and different perspectives on the relevance of the uncertainties involved leaves us in a state of ignorance and ambiguity and thus beyond the conditions for using the UNESCO principle. But then the principle will have a very restricted validity area compared to most versions of the precautionary principle, and we are still left with the problem to determine what can be characterized as uncertainty and what as ignorance and ambiguity.

\section{Serious and Effectively Irreversible}

In a similar vein, what is to count as serious harm to nature is based on contestable value judgments that are not self- evident. Mankind has always interacted with nature and done alterations to the natural environment for better or worse. Since nature can be described as an indefinite number of interconnected self-adjusting biological systems, 'harm' becomes context-dependent. Destruction of some elements of an ecosystem, inevitably gives advantages to other elements, ensuring that harm in most cases is simultaneously a benefit. For instance, farmed salmon will escape or be released, and the escaped salmon will compete with wild salmon for food, habitats and spawning grounds. Escaped farmed salmon may also spread parasites and diseases and through mating with wild salmon change the genetics of the wild salmon population [12]. 
Genetic interaction between farmed and wild salmon population can cause reduced mean fitness and lower reproductivity. At present we do not know whether the PLGA particles and vaccination will affect salmon reproducibility or survival in wild, but the possibility cannot be ruled out. Assuming improved fitness of farmed salmon, some would say that the escape of salmon with subsequent depletion of the wild stock due to interbreeding and competition, represent no harm. We still have wild salmon, although somewhat different from the original variety. Others will consider this to represent serious harm since a) the genetic interaction will result in reduced genetic diversity (although this may be contested), and b) the escaped farm salmon will replace the wild relative, which is problematic for our distinctions between nature and culture, expressed in the value placed by most people on the idea of naturalness. In this particular sense the escapee is less natural than the native salmon.

Clearly we cannot determine what is a serious interference with nature, and certainly not what is to count as serious harm unless we determine which aspects of nature and its functioning that is to be regarded as worth preserving as it is today. Thus the question of serious harm is correlated to conceptions of how to maintain and preserve nature and biodiversity [4]. The vagueness makes specific value based discussions needed which is also argued for in the UNESCO version of the principle. However, an environmental change does not necessarily imply an adverse effect as illustrated above with the case of escapes by farmed salmon. Hence we question whether participatory processes can guide the choice of action in such cases, and that consensus in society regarding the nature of harm to the environment can be achieved. Furthermore, such processes may only include those effects that are valued by the society as negative as for instance effects on specific species as butterflies etc. and leave out impacts on ecosystem as well as abiotic components.

Moreover, even if we agree on some change as clearly harmful, the phrase "irreversible harm" is difficult to use in an uncontroversial technology assessment. For instance, the PLGA particles may be distributed by escape or release of vaccinated fish, and by accidental release of the vaccine. In aquatic environments use of PLGAs may be irreversible since they can be distributed over vast areas, distances, and possibly pass physical and physiological barriers. However, as polyesters in nature, these polymers undergo hydrolysis after administration, forming biologically compatible and metabolizable moieties (lactic acid and glycolic acid) that are eventually removed from the body by the citric acid cycle [2]. Since PLGA undergoes such a hydrolysis they will most probably be degraded short time after administration and hence involves a low plausibility for distribution into the environment. On the other hand, these particles are to be distributed at nanolevels that entail that different biological and physiological effects may occur. For instance, studies have shown that toxicity of particles increases with the decrease of particle size and increase of overall surface area [18]. Evaluation of the factors that affect nanomaterial exposure requires measurement of properties as particle size, shape, surface area, and surface chemistry with implications for the safety by application. Although the PGLA nanoparticles are biodegradable they may also have higher reactivity due to their increased surface area; hence have a potential to interfere with natural processes. These problems could be classified as matters of scientific ignorance rather than uncertainty, and be relegated beyond the scope of precaution. But as these altered properties are based on documented research, there is a case for according the plausibility by a case-by-case approach based on previous or analogous use and in relation to the novelty at the nanolevel, and thus as matters of uncertainty.

The most prevailing questions that need to be answered in relation to the environmental and health implications of nanomaterials are: What are the fate and transport mechanisms of nanoparticles? Which exposure routes are relevant? How do nanoparticles impact the natural environment including animal and human health? Vaccines with PLGA as carrier may be released during vaccination and from the vaccines. Although the PLGA is biodegradable, it is at present not known if the PLGA used in vaccines may have changed biodistribution patterns as well as persistence. Although encapsulation ensures more direct uptake by cells it also entails release of the antigens over extended periods of time. Another issue concerns PLGAs adsorption tendency and degree of aggregation at a macro versus a smaller level that also need to be investigated. Predatory animals can also spread the PGLA and the vaccines in the environment. Accord- 
ingly, there is a need to initiate experiments with the purpose to investigate the stability of PGLA particles in aquatic systems, uptake in aquatic organisms, including marine fish and mammals. But even if these acts represent irreversible alterations to the environment, it is not obvious that they represent harmful alterations. Also after we establish with reasonable certainty the extent to which PGLA based vaccines have irreversible effects on the environment, we still depend on value judgments to decide whether this is harmful.

In this context it is worthwhile to bear in mind the early days of the debate surrounding genetically modified organisms, where several proponents of growing genetically modified plants commercially pointed out that no escape of transgenes to wild relatives had been recorded, and it was unlikely that it would happen on any significant scale. When such escape was documented some years later, the proponents of the genetically modified crops did not see this as a problem for their conception of this as a fruitful technology. Typical arguments are that transgenes generally give the wild plants small competitive advantages and transgene spread should not be considered to be more harmful to the environment than gene flow from traditional plant breeding crops $[31,33]$. Despite the fact that this spread is irreversible, many consider this spread to represent acceptable harm. We can also imagine that if these transgenic wild plants became 'superweeds' [16], threatening both crops and the diversity of ecosystems, the same people could merely say that this is no significant harm when considering the benefits of the transgenic crops, the wide array of herbicides we have to use to control the weed, and how much nature we have left that will never be affected by these weeds.

Even when there is some case of irreversible and in several ways destructive changes due to human activity; we still depend on contestable values to give meaning to concepts such as 'harm', because they are both descriptive and normative. We have to determine their normative content to be able to use them as action guiding, and this can only be done through the discussion of actual cases, as is clearly the intention of the UNESCO principle. But in this area the UNESCO version stumbles on similar problems as the strong versions, such as the Wingspread statement. It is not enough to state that plausible threats of irreversible harm should lead to precautionary meas- ures, as long as we have no way to ascertain what is to count as 'harm'. Furthermore, in the UNESCO version the concept of morally unacceptable harm is interlinked with serious and effectively irreversible which is problematic. How can these terms be used to choose the best action in an open and flexible way? The question of what is to count as harm is highly dependent on a scientific analysis, involving both the disciplines involved in development of the technology in question as well as they who have competence in ecology and biology. Moreover the complexities of the technical issues of novel technological products do also represent insurmountable obstacles to a wellinformed public value discussion. Hence, we will argue that instead of using participatory processes for choosing actions, a better approach would be to identify different societal conceptions that can be used in comparison with the present biological and ecological understanding [32].

\section{Inequitable to Present or Future Generations}

Inequitable distribution certainly is morally wrong, but how is it possible to estimate distribution of benefits and harm of future applications of a new technology? There is a wide and growing discussion on global justice $[39,40,43,45]$ that demonstrates some of the difficulties in determining what is to count as an equitable global distribution of goods and burdens among people living today. Solving this question as part of a precautionary approach to particular technology applications does not seem any easier. Of course, in many cases this point will most likely be irrelevant, for example when discussing vaccines in fish. But when it is relevant, as is the case with nanotechnology and biotechnology related issues such as patenting, bioprospecting and strategies for funding of research and development, the issues must be solved in an inclusive debate rather than as part of employing the precautionary principle to a particular technology application. We assume this point is included in the UNESCO version of the principle mainly to avoid the charge that the real suffering of existing people is sacrificed for potential suffering of future generations.

The issue of equity in relation to precautionary thinking seems more relevant regarding future generations. But equity concerns reasonable distribution between members of the same society, be it a local or 
a global community. We do not have this relationship with future generations, and we are unable to share goods with them on an equitable scale since we do not know who they are, how many they will be or what their interests will be. If we extrapolate from known history, we can safely conclude that these essential facts are impossible to predict. 'Equity' is not a suitable moral concept in this context, since it is connected to an ethics of reciprocity. Hans Jonas [22] suggests that responsibility is a more basic ethical principle than reciprocity since there can be no reciprocity between future generations and us. For Jonas, the fundamental lesson of technology development is the power humankind has acquired, that in the last instance enables us to destroy the possibility of any future human life on earth (Ibid. 26f.). Thus he suggests a new categorical imperative to replace the Kantian: 'Act in a way that makes the consequences of your acts conform with the permanent real human life on earth.' (Ibid. 36)

Another important and new moral challenge according to Jonas concerns our shared responsibility, since our acts are collective acts. The moral imperative becomes political. Our responsibility for future generations must be at the core of any precautionary thinking, and the UNESCO version commendably incorporates this. This is, however, not a matter of equity but of responsibility in the sense employed by Jonas. We should leave an earth that gives coming generation the opportunity to decide what kind of life they want to lead. Environmental responsibility relates to human existence, and suggests that the Earth should not be left in a worse state than the state in which we received it.

Perhaps Jonas' perspective on environmental responsibility implies a precautionary approach; but he adds an important caveat. We have a duty to gain knowledge in order to contribute to the good of future generations, which implies the acceptance of uncertainty (Ibid. 28), while at the same time encouraging innovation. A restrictive precautionary policy may prevent rather than promote the future state of the earth. Rather than a narrow interpretation of the precautionary principle with emphasis on 'avoidance of harm', the focus in an ethics of a responsibility approach is directed to how we should promote a good life also for future generations. In this context vaccines in general may help to ensure a more stable production in aquaculture which is important in both rich and poor countries but also for posterity. Although we cannot know the preferences of future generations, we can be certain that a stable and sustainable food supply will be as essential for them as it is for us. On the other hand, genetic pollution may reduce the possibility of finding and developing alternative sources of food production. It has been argued that fish farming involving carnivorous species is not sustainable as it is practiced today [36], and future food production may have to develop new ways of exploiting marine food resources. If the use of PLGA as carriers of vaccines in fish farming endangers this opportunity, we have to deem it morally unacceptable. But we do not need the precautionary principle to discover that it is wrong to undermine alternative marine sources of food production. Jonas' ethics of responsibility is more suitable in that respect.

As illustrated above, this ultimately raises the following questions; for whom may PGLA as carriers for vaccines be morally unacceptable, and which moral theories or principles should be employed? For instance, the biotechnology industry advocates acceptable environmental and health impacts of DNA and GM vaccines while others claim there are unacceptable impacts. PGLA has been approved by the FDA based on their history for use in clinical applications [29]. Does the use at a nanolevel represent new concerns? Does the distribution to a new organism, fish, represent new questions? Does the shift from medical application at a low level to large-scale distribution in aquaculture involve new challenges for control and monitoring? These issues require research by different groups of scientists for identification of potential impacts. Unless we have some indications of the answers to these questions, the UNESCO principle's demand of precautionary action against interventions that are inequitable to future generations' will remain mere words. But the report does provide a promising procedure for how to avoid this charge.

Participatory Case-Based Approach as Solution?

So how does the UNESCO version attempt to avoid the vagueness trap of precautionary thinking? The answer may be found in the final demand of a participatory process that shall include all affected parties. The report claims that 'moral judgments are 
less subject to plurality and rest on a firmer basis than the ethical theories one adheres to' [49] and expresses a belief in a yet undiscovered universal basis for ethics, forcefully stated by several previous authors (see e.g. Jonsen and Toulmin [23]). Thus we are more likely to reach consensus as a result of the process. This belief in a tendency towards moral agreement in particulars is basis for expecting generally acceptable and more stable results of the participatory deliberation.

Participatory processes are in the vogue in present day technology governance. Engaging the public is usually justified through some kind of stakeholder theory [42] or deliberative democracy theory [7]. Although there are overlapping ideas between the two approaches, a deliberative democracy approach is more in keeping with the normative ideals in the UNESCO report. According to this approach, democratic decision-making is expressive of mutual respect and of justice. It provides a wider argumentative basis for decisions [19] as lay people may have unique, valuable contributions to complex and controversial political issues [7,55]. In Stirling's [47] analysis of the rationale for public engagement, he highlights in addition the role of public engagement in restoration of legitimacy and public trust. The issue of trust has also been argued by Macnaghten et al. [30], who considers that engagements represent an extraordinary opportunity to build a robust prospective role for the social sciences in shaping the future of nanotechnology research and innovation processes.

One crucial problem with participatory processes is the fact that many people have no wish to spend time on them, due to their lack of relevant knowledge and lack of interest in entering extensive learning processes, as is demonstrated in several focus groups and interviews $[21,46,48]$. Therefore we should ask why it is important to involve the public in discussions of issues where they may lack both knowledge and the inclination to participate.

If we assume that a participatory process can give valuable results, we still have to question the assumption that this process will result in a stable normative consensus. Participatory processes open up for a plurality of views and conflicting perspectives that create a dilemma concerning how and when to reach a decision, since the aim of any participatory process in relation to the precautionary principle is generating information for decision-making. The UNESCO report fails to present evidence for the claim about particular moral judgments being less subject to plurality, and the disagreement on how to deal with the more or less plausible harms from distribution of any vaccines to be used in aquaculture hardly supports their case. On the contrary; almost everybody agrees on the theoretical assumption that irreversible damage is wrong, but disagrees on the particulars, and on the strategies for handling such harm. Thus there is no guarantee that staying with moral judgments of concrete cases will help us resolve the moral issues involved.

In many cases the reason for disagreement is not moral, be it theoretical or practical, but one of plausibility of risks. For instance an analysis of the evolution of policy discourses [8] on nanotechnologies indicated that, while gradually more participants enter the public debate, the issues of concern have become more narrowly defined. After a phase where nanotechnology emerged on public and policy agendas, and a subsequent one in which debate about a wide range of implications of the possibly radical potential of nanotechnologies was expanding, a global policy discourse that focuses primarily on environmental, health and safety risks is now gaining grounds. As Doubleday writes:

'So rather than addressing questions of how particular conceptions of health and the human body are reproduced by nanotechnology research programmes, the dominant vision of nanotechnology as a public issue concentrates on the toxicology of nanoparticles.' (Ibid., p.213)

The disagreement often concerns what future scenarios that are likely, not the ethics of dealing with these scenarios. The discussion can also be framed as a psychological one rather than a factual or a moral disagreement: risk-averse versus riskaccepting personalities, although it is reasonable to regard the psychological state to some extent to be interdependent on beliefs [24]. In short, the assumption that disagreement is moral and can be resolved through discussing cases rather than theories and principles appears to be misguided. In issues like these it is even difficult to construct meaningful distinctions between empirical facts and value judgments. For instance, with PLGA as carriers of 
vaccines there are at present lack of empirical data and no scientific consensus of the various type of uncertainty embedded with its use. The problem is the issue regarding identification and interpretation of relevant data and approaches for gathering more data rather than how to handle these data in practical reality.

Even if the UNESCO definition of the precautionary principle clearly is more specific and a better guide for regulation than the paradigmatic weak and strong versions preceding it, the UNESCO version stumbles on the assumption about less plurality in moral judgments. We have no reason to expect this because interpretations of the issues at stake differ, as is exemplified by the continuing debate between Europe and the USA, Canada and Argentine on the moral acceptability of the release of genetically modified organisms [52].

\section{Responsibility Versus Precaution}

The UNESCO version replaces scientific probability with plausibility, and emphasizes proportionality of action relevant to 'the seriousness of the potential harm, with consideration of their positive and negative consequences, and with an assessment of the moral implications of both action and inaction.' In this way it is neither reducible to a demand for risk assessment nor an unreflexive obstacle to technological progress due to a myopic risk perspective. But assuming that the precautionary principle is meant to be action guiding, the UNESCO principle provides no way to decide what is to count as scientific plausibility in a situation of scientific disagreement. Especially in new and controversial areas of research, such disagreement is common.

The UNESCO report is right in that the responsibility for making a decision on technology applications is and should be political mediated by a wide, open and responsible debate in accordance with the ideal of deliberative democracy [7]. The debate must be based on best scientific knowledge. We will argue that this calls for a privileged position for experts (natural and social scientists, as well as ethicists) in accordance with Aristotle's theory of practical argumentation where accepted opinions (endoxa) include those of the majority as well as those of the majority or the most respected of the wise, i.e. the experts [3].
The Aristotelian privileging of expertise does not express elitism or disrespect for the rationality of lay people, but a reasonable assumption about the value of knowledge and understanding gained from years of specialization in theory and practice. As emphasized above, lay people have an important role to play in these debates, since they can represent an outside view, serving as corrective to myopic tendencies both within the nanotechnology community as well as within nanoethics. Moreover it has also been argued that lay people may see matters that the experts discount or fail to notice since they are immersed in the scientific culture with its epistemological and ethical assumptions [55].

In the current governance debate, however, the belief in the value of public participation is too strong. As we have pointed out, there is evidence that lay people themselves reject this role. Since they present sound arguments for this rejection, in addition to 'voting with their feet', using deliberative democracy theory to say that they should get involved is a self-defeating exercise. In several of the studies, lay people express that they either do trust experts or that they wish to do so. This can be read as an implicit claim that the experts should be trustworthy, in the sense that they should take responsibility for the moral acceptability of what they do.

In order to fill that role of taking responsibility in our current project, we need scientific studies of the effects prior to using the nanoparticle based products commercially, where scientists determine the uncertainties and suggest the range of possible outcomes which is subsequently followed up by targeted research. However, with regard to nanotechnology there are reasonable disagreement on the range of outcomes and the plausibility of the different outcomes. Hence, even if everybody agrees to the list of principles for delimiting relevant harm, we will disagree on how to balance different scientific scenarios. For example, the different scientific disciplines that are presently involved in the epistemic debate employ competing models or analogies for basic assumptions on how to frame the scope for further research as well as with regard to regulative frameworks. Since the principles and paradigms of the different scientific disciplines differ, they have no common ground to discuss means for gathering new scientific understanding. 
In this sense the ethics of responsibility is related to a precautionary approach that emphasizes the necessity of initiating risk-associated research [53]. Such risk-associated research entails that the scientists should identify uncertainty and that they should discuss the evidence and arguments for the differing assumptions and communicate this disagreement to the public and political authorities. Potential threats pointed out by respected scientists with relevant education and practice, threats that the scientists at the moment are unable to indicate the likelihood of, should be communicated as part of the studies. Recognizing fallibility is an inherent part of scientific practice, and scientists should always regard unexpected damage to be likely when introducing beneficial new technology.

But who are the experts that should be involved in a best scientific practice approach as the one we suggest here? That depends on what scientific knowledge is relevant for the examination of risks and uncertainties with regard to environmental, health, social and economic effects. Valuable insights can be drawn from science and technology studies and the debate on precaution where a central point has been the integration between new technology and modern democratic society, making the social and normative essential and internal parts of the technology rather than mere additions and external [42]. Regulation of the development and use of nanoparticles as carriers for vaccines is obviously not merely a question of nanotechnology and aquaculture. The scientific evaluation group should encompass a wide range of experts, including immunologists, biologists, marine ecologists, sociologists and ethicists.

The scientists should not restrict themselves to scientific work in a narrow sense. Their research is based on certain values and will have consequences for nature and society. They have a duty to question the soundness of these values and to evaluate the consequences should be regarded as good or acceptable - or they should ensure that somebody else does this reflexive examination. Since most scientists lack the background and resources necessary for this kind of ethical analysis, their duty to assess the values and implications of their research activity would be fulfilled if their research integrates social science and ethics per- spectives on the relevant science and technology. This should not be regarded as 'outsourcing' of ethics, as is often done in ELSA-research. The scientists have a duty to take part in mutual learning processes with the humanities researchers through discussion of the technology in this societal and ethical perspective. Only by this interdisciplinary cooperation can the public be given resources that are valuable for their participation in an open debate of the relevant issues. Hence, our approach can be considered as a return to a principle of best scientific practice based on an ethics of responsibility.

To avoid morally unacceptable consequences for future (or even present) inhabitants of the earth, we need to pay heed to the words of the scientific community and combine it with common sense expressed in the ethics of responsibility. We have a moral responsibility to anticipate and prevent negative consequences irrespective of the degree of human contribution to the potential harm. This kind of responsibility is not fully captured in precautionary thinking where only human activity triggers the moral obligation. Thus the problem lies in the collective nature of responsibility [22].

There are incentives that seek to promote a broad sense of responsibility [26] such as the EU's 'Code of Conduct for Responsible Nanosciences and Nanotechnologies Research' [6] and voluntary measures. However, we see the concept of responsibility not to only endorse and stimulate reflective awareness in order for researchers to be able to communicate some of the issues at stake to the general public or enable the scientists to reflect on the conditions they perform their research under, as well as the choices they make. It is also about enhancing deliberation on the course of action of all stages of the development process that leads to the context of the end user in ways that for instance will realize the expressed deliverables promised to and endorsed by public bodies. In order to carry out this kind of responsibility reflection, scientific and technological expertise must be supplemented with ethical expertise. Although one can discuss to what extent deciding on the good is an area of expertise, systematic normative reflection certainly is [44]. Thus, some kind of interdisciplinary expert-based reflexive work is necessary in order to fulfil the demands of scientific responsibility. 


\section{Conclusion}

There are many formulations and versions of the precautionary principle, and the debates raised by formulations of the principle have been valuable for recognizing a changed role for science and technology in democratic societies. Most attempts at workable formulations of the principle, however, have been met with criticism for either being vacuous or too narrow and leaving too much to discretion. Although the UNESCO version makes the best attempt so far to avoid these pitfalls, it does not fully succeed, also this version is plagued by vague key concepts and questionable normative assumptions.

We suggest instead that the precautionary principle need to be supplemented by combining the ideal of best scientific practice with the insights of Jonas' ethics of responsibility to ensure a sound basis for political decisions on technology regulation. On controversial issues where the stakes are high and facts contested, such as use of nanotechnology, valuable insights from the debate on precaution is retained, but futile attempts at finding a formulation of a particular principle is replaced by a regulatory approach based on a wide scientific evaluation of the values and implications of particular technology applications. This represents no attempt at solving the problems in the definition and application of the precautionary principle, nor does it avoid the vagueness problems. We wish to redirect the attention towards the issue of scientific and political responsibility as an alternative framework for the discussion of how to handle potentially harmful use of new technology. This responsibility is aimed at scientists as we consider expert arguments will and should carry more weight than public argument since they have the responsibility for making a thorough and sound assessment of the technology and share their best opinions with the public and political authorities. Involving lay people should be a way to widen our perspectives, and we should be careful to avoid shifting the burden of responsibility from politicians to the general public.

Acknowledgement We will express our gratitude to Matthias Kaiser for his generous criticisms and many suggestions for improvements to this paper. He obviously does not agree with several of our key arguments and is not responsible for any weaknesses of this paper.
Open Access This article is distributed under the terms of the Creative Commons Attribution Noncommercial License which permits any noncommercial use, distribution, and reproduction in any medium, provided the original author(s) and source are credited.

\section{References}

1. Anderson JM, Matthew SS (1997) Biodegradation and biocompatibility of PLA and PLGA microspheres. Adv Drug Deliv Rev 28:5-24

2. Athanasiou KA, Niederauer GG, Agrawal CM (1996) Sterilization, toxicity, biocompatibility and clinical applications of polylactic acid/polyglycolic acid copolymers. Biomaterials 17:93-102

3. Aristotle (1960) Topica. Harvard University Press, Harvard

4. Arntzen S (2001) Integrity and uses of nature. Glob Bioeth Probl Bioetica 14:67-75

5. CBD (Convention on Biodiversity) (2000) Cartagena Protocol on Biosafety to the Convention on Biological Diversity. (Montreal: Secretariat of the Convention on Biological Diversity) Retrieved December 16, 2010 from http://bch.cbd.int/protocol/text/

6. CEC (2008) Code of conduct for responsible nanosciences and nanotechnologies research. Commission of the European Communities, Brussels

7. Cohen J (1997) Deliberation and democratic legitimacy. In: Bohman JF, Rehg W (eds) Deliberative democracy. Essays on reason and politics. MIT, Cambridge, pp 67-91

8. Doubleday R (2007) Risk, public engagement and reflexivity: alternative framings of the public dimensions of nanotechnology. Health Risk Soc 9:211-227

9. EEA (European Environment Agency) (2002) Late Lessons from Early Warnings: The Precautionary Principle, 18962000. Retrieved December 15, 2010, from http://www.eea. europa.eu/publications/environmental_issue_report_2001_22

10. EC (Commission of the European Communities) (2000) Communication on the Precautionary Principle, (COM (2000) 1, 02-02-2000). Retrieved December 16, 2010 from http://ec.europa.eu/environment/docum/20001_en.htm

11. European Union (2006) Consolidated Versions on the Treaty on the European Union and of the Treaty Establishing the European Community. Retrieved February 22, 2011, from http://eurlex.europa.eu/LexUriServ/LexUriServ.do?uri=OJ: C:2006:321E:0001:0331:EN:PDF

12. Ferguson A, Fleming IA, Hindar K, Skaala Ø, McGinnity P, Cross TF, Prodöhl P (2007) Farm escapes. In: Verspoor E, Stradmeyer L, Nielsen J (eds) The Atlantic Salmon: genetics, conservation and management. Blackwell, Oxford, pp 357-398

13. Freese W, Schubert D (2004) Safety testing and regulation of genetically engineered foods. Biotechnol Genet Eng Rev 21:299-324

14. Foster KR, Vecchia P, Repacholi MH (2000) Science and the precautionary principle. Science 288:979-981

15. Gardiner SM (2006) A core precautionary principle. J Polit Philos 14:33-60

16. Gilbert N (2010) GM crop escapes into the American wild. Nature News, 6 August 2010. Retrieved December 15, 
2010, from http://www.nature.com/news/2010/100806/full/ news.2010.393.html

17. Goklany IM (2001) The Precautionary Principle; A critical appraisal of environmental risk assessment. Cato Institute, Washington DC

18. Grieger KD, Hansen S, Baun A (2009) The known unknowns of nanomaterials: describing and characterising uncertainty within environmental, health and safety risks. Nanotoxicology 3:222-233

19. Gutmann A, Thompson D (2004) Why deliberative democracy? Princeton University Press, Princeton

20. Hacking I (1986) Culpable ignorance of interference effects. In: MacLean D (ed) Values at risk. Rowman and Allanheld, Totowa, pp 136-154

21. Hoeyer K (2003) 'Science is really needed - that is all I know': informed consent and the non-verbal practices of collecting blood for genetic research in northern Sweden. New Genet Soc 22:229-243

22. Jonas H (1979) Das Prinzip Verantwortung. Suhrkamp Verlag, Frankfurt am Main

23. Jonsen AR, Toulmin S (1988) The abuse of casuistry. a history of moral reasoning. University of California Press, Berkeley

24. Kaiser M (1997) Fish-farming and the precautionary principle: context and values in environmental science for policy. Found Sci 2:307-341

25. Karlsson M (2006) The precautionary principle, Swedish chemicals policy and sustainable development. J Risk Res 9:337-360

26. Kjølberg KL, Strand R (2011) Conversations about responsible nanoresearch. Nanoethics (crossreference to this number)

27. König A, Cockburn A, Crevel RWR, Debruyne E, Grafstroem R, Hammerling U, Kimber I, Knudsen I, Kuiper HA, Peijnenburg AACM, Penninks AH, Poulsen M, Schauzu M, Wal JM (2004) Assessment of the safety of food derived from genetically modified (GM) crops. Food Chem Toxicol 42:1047-1188

28. Kvakkestad V, Gillund F, Kjølberg K, Vatn A (2007) Scientists' perspectives on the deliberate release of GM crops. Environ Values 16:79-104

29. Lü J-M, Wang X, Marin-Muller C, Wang H, Lin PH, Yao Q, Chen C (2009) Current advances in research and clinical applications of PLGA-based nanotechnology. Expert Rev Mol Diagn 9:325-341

30. Macnaghten P, Kearnes MB, Wynne B (2005) Nanotechnology, governance, and public deliberation: what role for the social sciences? Sci Commun 27:268-291

31. Messeguer J (2003) Gene flow assessment in transgenic plants. Plant Cell Tissue Organ Cult 73:201-212

32. Meyer G, Folher AP, Jørgensen RB, Krayer von Krauss M, Sandø P, Tveit G (2005) The factualization of uncertainty: risk, politics, and genetically modified crops - a case of rape. Agric Hum Values 22:235-242

33. Miller HI (1997) Policy controversy in biotechnology: an insider's view. Academic, San Diego

34. Morris J (2002) The relationship between risk analysis and the precautionary principle. Toxicology 181-182:127-130

35. Myhr AI (2010) A precautionary approach to genetically modified organisms: challenges and implications for policy and science. J Agric Environ Ethics 23:501-525
36. Naylor RL, Goldburg RJ, Primavera JH, Kautsky N, Beveridge MCM, Clay J, Folke C, Lubchenco J, Mooney H, Troell M (2000) Effect of aquaculture on world fish supplies. Nature 405:1017-1024

37. Nielsen KN, Fredriksen BN, Myhr AI (2011) Mapping uncertainties in the upstream: The case of PLGA nanoparticles in salmon vaccines. Nanoethics 5, this issue

38. O'Riordan T, Cameron J, Jordan A (eds) (2001) Reinterpreting the precautionary principle. Cameron May, London

39. Pogge T (ed) (2001) Global justice. Blackwell, Oxford

40. Pogge T (2002) World poverty and human rights: cosmopolitan responsibilities and reforms. Polity, Oxford

41. Raffensperger C, Tickner J (eds) (1999) Protecting public health and the environment: implementing the precautionary principle. Island, Washington, DC

42. Ravetz J (2004) The post-normal science of precaution. Futures 36:347-357

43. Rawls J (1999) The law of peoples. Harvard University Press, Cambridge

44. Singer P (1972) Moral experts. Analysis 32(4):115-117

45. Singer P (2002) One world. The ethics of globalization. Yale University Press, New Haven

46. Skolbekken J-A, Ursin LØ, Solberg B, Christensen E, Ytterhus B (2005) Not worth the paper it's written on? Informed consent and biobank research in a Norwegian context. Crit Public Health 15:335-347

47. Stirling A (2008) Opening up or closing down? Power, participation and pluralism in social appraisal of technology. Sci Technol Human Values 33:262-294

48. Tait J (2009) Upstream engagement and the governance of science. EMBO Rep 10:S18-S22

49. UNESCO COMEST (2005) Report of the Expert Group on the Precautionary Principle of the World Commission on the Ethics of Scientific Knowledge and Technology (COMEST). Retrieved December 10, 2010, from http:// unesdoc.unesco.org/images/0013/001395/139578e.pdf

50. UNEP (United Nations Environment Programme) (1992) Rio Declaration on Environment and Development. Retrieved December 15, 2010 from http://www.unep.org/Documents. Multilingual/Default.asp?documentid $=78$ \&articleid $=1163$

51. Weaver SA, Morris MC (2005) Risks associated with genetic modification; a annotated bibliography of peer reviewed natural science publications. J Agric Environ Ethics 18:157-189

52. Weiss C (2006) Can there be science-based precaution? Environmental Research Letters, 1 (1). Retrieved November 15, 2010, from www.iop.org/EJ/abstract/1748-9326/1/1/ 014003/

53. Wickson F, Gillund F, Myhr AI (2010) Treating nanoparticles with precaution: recognising qualitative uncertainty in scientific risk assessment. In: Kjølberg K, Wickson F (eds) Nano meets Macro: social perspectives on nanoscale sciences and technologies. Pan Stanford Publishing, Singapore

54. Wiener JB, Rogers MD (2002) Comparing precaution in the US and Europe. J Risk Res 5:317-349

55. Wynne B (1992) Uncertainty and environmental learning: reconceiving science and policy in the preventive paradigm. Glob Environ Change 2:111-127 